\title{
La carnavalización del discurso naturalista en $A$ fuego lento, de Emilio Bobadilla
}

Joan Torres-Pou

Florida International University, Miami

\section{RESUMEN}

Estudia la obra del novelista cubano Emilio Bobadilla, autor de una original novela no consolidada por el canon crítico. La dicotomía entre civilización y barbarie es el cimiento temático y discursivo de $A$ fuegolento, perola novela discurre por los caminos de la parodia y de la carnavalización. Mediante un análisis de contenidos, de personajes y de estrategias se muestra una profunda crítica a los discursos sobre la modemización de Hispanoamérica.

\section{Abstract}

This study is about the work of the Cuban novelist Emilio Bobadilla, the author of an original novel which has not yet been too well accepted in the literary canons. The dichotomy between civilization and barbarism is the thematic and literary basis of $A$ fuego lento, but the novel uses parody and carnival. By means of an analysis of contents, characters and narrative strategies, discourse on the modernization of Latin America is deeply criticized.

En 1903 apareció, dentro de la colección Biblioteca de novelistas del siglo XX, publicada en Barcelona por Heinrich y Cía., la misma editorial que había editado Amor y pedagogía de Miguel de Unamuno y La voluntad de Azorín, A fuego lento de Emilio Bobadilla (18621921). Dos años antes, Bobadilla había publicado una serie de cuentos 
titulada Novelas en germen (1900), pero, por lo que era realmente conocido, era por sus acerbas críticas literarias que incluso lo habían llevado a enfrentarse, algo más que verbalmente, con reconocidas figuras de la literatura española. Así, los comentarios que le hiciera al autor de La regenta, Leopoldo Alas, "Clarín", fueron la causa de un duelo del que, al parecer, este último no salió muy bien parado, pero que aumentó la popularidad de "matón literario" que tenía Bobadilla" .

Desdichadamente, a pesar de que Bobadilla fue uno de los escritores cubanos de mayor difusión en su época, una serie de factores se conjuraron para que su nombre fuera poco conocido en nuestros días. Ante todo, las guerras entre Cuba y España hicieron que su familia pasase más tiempo en el extranjero que en Cuba, por lo que Bobadilla sólo vivió en la isla parte de su infancia y algunos de los años de paz relativa que separaron la Guerra de los Diez Años de la Guerra de la Independencia; el resto de su vida lo pasó en distintos puntos de América y Europa. En particular, vivió en España y Francia, donde murió ostentando el cargo de cónsul de Cuba en Biarritz. Así pues, su labor literaria se realizó fuera del país y, por lo tanto, la temática de sus obras, excepción hecha de las alusiones que podemos encontrar en $A$ fuego lento y en algunos de sus cuentos, no tiene un carácter marcadamente cubano. Por otro lado, a pesar de su apoyo a la causa independentista, Bobadilla pasó la Guerra de la Independencia en el círculo de emigrados cubanos en París, por lo que no tuvo esa relación directa con la nación en su momento más crítico que quizá le hubiera valido un lugar entre los escritores de la revolución. Por último, el descrédito de la narrativa hispanoamericana anterior al boom, el carácter ideológico en que se basaron la mayor parte de las recuperaciones de textos decimonónicos efectuadas por académicos del siglo xx y el aislamiento de la cultura cubana respecto a la academia estadounidense, que tanto ha contribuido en décadas recientes a la revalorización de la

1. Salvador Bueno, en el prólogo a la edición de 1965, menciona que el escritor argentino Manuel Ugarte llamaba a Bobadilla y al puertorriqueño Luis Bonafoux "terroristas de las letras y matones literarios", Salvador Bueno, "Fray Candil en una novela", prólogo a Emilio Bobadilla (Fray Candil), A fuego lento (La Habana: Editorial de la Universidad de La Habana, 1965) XIl. 
literatura latinoamericana, fueron factores que determinaron que se descuidara el estudio de la obra de Bobadilla.

Aparte de una extensa labor periodística, la producción literaria de Bobadilla comprende varios poemarios, cuentos, obras teatrales que nunca fueron impresas, y tres novelas, entre las que destaca $A$ fuego lento. El tono predominante de su creación es el satírico, que también fue el que mejor caracterizó su quehacer periodístico. En lo que respecta a la escuela en que se adscriben sus novelas, el mismo autor declaró en Reflejos de Fray Candil (1886): "no sé a punto fijo la escuela literaria a la que pertenezco... pero aquí inter nos: estoy en peligro de caer del lado del naturalismo si es que no he caído ya".

Cuando en 1886, Bobadilla hacía esta afirmación de simpatía estaba todavía lejos la aparición de A fuego lento. En este texto podemos constatar que el escritor cubano no se limitó a seguir los parámetros de la escuela naturalista, ya que en lugar de of recernos una novela experimental, lo que hace es parodiar el discurso naturalista para satirizar el desencanto cientificista con que los intelectuales hispanoamericanos de fin de siglo contemplaban los resultados de su afán civilizador. Con ella, el autor nos of rece una obra totalmente original en su momento, que, en lo que tiene de hiperbólica y de carnavalización, anticipa algunos de los rasgos propios de la literatura hispanoamericana de mediados del siglo xx.

A fuego lento narra la historia de Eustaquio Baranda, médico exiliado en París, quien llega a una localidad tropical después de haber participado en una abortada revolución en su país. Conoce a Alicia, una joven india, pupila de su anfitrión, el comerciante Olimpio Díaz, la seduce y se la lleva con él a París donde se casan. En París, se revela lo distinto de sus respectivas personalidades, reflexiva y pasiva la del médico e instintiva y activa la de su esposa. Asimismo, una concepción de la vida diametralmente opuesta, junto al desamor de Baranda y a los celos y el despecho de Alicia, hace que los cónyuges entren en una espiral de disputas que, con sus consabidos disgustos y violencias, minan la salud del pacífico Baranda y terminan con su vida. 
Mediante esta aparentemente superficial historia de desavenencias matrimoniales, Bobadilla replantea de manera tragicómica un tema común en la literatura hispanoamericana, el de la civilización y barbarie. Efectivamente, el matrimonio entre el europeizado Baranda y la india Alicia no es sino la encarnación de la conocida dicotomía que, según los intelectuales hispanoamericanos del siglo XIX, era la causa de los problemas que aquejaban a sus inestables naciones. Ahora bien, a diferencia de escritores como Esteban Echeverría o Domingo Faustino Sarmiento, quienes esperaban el triunfo de la civilización sobre la barbarie, Bobadilla comparte el sentimiento de los intelectuales de fin de siglo, los cuales reconocían no haber podido triunfar sobre la barbarie. Pocos fueron en ese momento los que, como el cubano José Martí, advirtieron que el verdadero problema no estaba entre la civilización y la barbarie, sino entre la falsa erudición y la barbarie. Los más se dejaron llevar por teorías deterministas y concluyeron que el fracaso se debía a la degeneración de la raza encargada de transmitir la civilización, la cual carecía del vigor necesario para esta empresa, y a la incapacidad de las razas mestizas ante el orden y el progreso social $^{2}$. Los personajes de Bobadilla expresan este sentir, pero el carácter humorístico de su novela presenta un marcado dialogismo de este subgénero narrativo, por lo que no encontramos una tesis explícita; antes bien, en la cita de Flaubert con que se inicia el relato se nos desafía a desentrañar la moral que encierra el texto: "Si le lecteur ne tire pas d'un livre la moralité qui doit s'y trouver, c'est que le lecteur est un imbécile ou que le livre est faux au point de vue de l'exactitud"3.

2. En "Nuestra América", José Martí dice: "Por eso el libro importado ha sido vencido en América por el hombre natural. Los hombres naturales han vencido a los letrados artificiales. El mestizo autóctono ha vencido al criollo exótico. No hay batalla entre la civilización y la barbarie, sino entre la falsa erudición y la naturaleza". José Martí, "Nuestra América" en Política de Nuestra América (México: Siglo XXI, 1977) 39. En este sentido, Martí se opone a modernistas tales como José Asunción Silva y Manuel Díaz Rodríguez o a naturalistas como Eugenio Cambaceres, quienes, siguiendo la neurosis finiseculąr de la decadencia de Occidente, en sus novelas, consideran la derrota de sus protagonistas como causa de unos rasgos degenerativos determinados por descender de una estirpe que no es portadora del vigor necesario para afianzar la civilización sobre la barbarie.

3. Citado en Emilio Bobadilla, A fuego lento, ed. cit. En adelante se indicará solamente el número de página. 
Con el fin de encontrar este mensaje en $A$ fuego lento, es ante todo necesario aceptar que la novela se sustenta sobre la base de una oposición que representa la dicotomía civilización y barbarie y que esta oposición, determinada por el dialogismo, va a evitar el explícito predominio de un punto de vista sobre el otro. Consecuentemente, la novela se sitúa en dos espacios geográficos contrapuestos. La primera parte tiene lugar en Ganga y Guámbaro, ficticias localidades del trópico continental hispanoamericano, la segunda se desarrolla en París y satiriza la vida de la comunidad hispanoamericana establecida en esa ciudad y la tercera sucede en París y Onival-sur-Mer y se centra en el relato de la muerte "a fuego lento" del protagonista ${ }^{4}$. La oposición de estos espacios ficticios y reales, indefinidos y definidos como estructura fundamental de la novela insisten, por lo que representan, en la implícita propuesta temática ya mencionada de oponer la barbarie a la civilización.

Bobadilla había viajadopor Venezuela, Colombia, Panamá y las islas del Caribe hispano. Por lo tanto, conocía muy bien el trópico hispanoamericano y de acuerdo con las teorías científicas en boga, su texto identifica como consecuencia de la herencia y el entorno aquellos males que se encuentran de manera general en esta parte del mundo ${ }^{5}$. Para tal fin, en la primera parte de su novela, parodia la

4. Onival-sur-Mer queda a poca distancia de París, en la región de Picardía, y, en la época que tiene lugar la historia, empezaba a desarrollar una incipiente industria turística, pero todavía era un lugar básicamente rústico al que solía ir Bobadilla y que le inspiró una de las crónicas de Con la capucha vuelta (crónicas) (París: Paul Ollendorff, 1909).

5. William Rosa, en "Mestizaje y sexualidad en A fuego lento: convergencia y divergencia", Confluencia 2 (1995) 76-86, afirma que la patria del protagonista es República Dominicana y que la novela de Bobadilla habla de la lucha del mestizo por ascender en la Cuba de la segunda mitad del siglo xIx. Tal interpretación no se sustenta en absoluto en el texto, ya que el autor evita hacer alguna mención que permita reconocer los lugares donde suceden los hechos. En el prólogo a la novela, Salvador Bueno cae en el mismo error en lo que respecta a la patria del protagonista. El hecho de que Baranda venga de una ciudad llamada Santo, probablemente les hace pensar que se trate de Santo Domingo, pero, en lo que respecta a la acción queda claro que transcurre en un país continental de cambio climático entre la costa y el interior, donde se encuentra la capital, lo que más bien hace pensar en Colombia. Asimismo, la voz narrativa hace énf asis en el hecho de que en el lugar existe una significativa población indígena. Ef ectivamente, la insistencia en el elemento indígena es evidente hasta en la identidad de la protagonista, que William Rosa conf unde con una mestiza, 
sociedad caribeña y pone al descubierto todos sus vicios de manera grotesca y exagerada. Así, los habitantes de Ganga, que ostentan nombres históricos rimbombantes como Newton, Olimpio o Epaminondas, matrimoniados con los apellidos más comunes, son unos inútiles a los que sólo les gustan las peleas de gallos y emborracharse, son tramposos y siempre piden prestado, las mujeres son idolátricamente religiosas y pasan el día tumbadas en hamacas sin pensar en nada. La voz narrativa, con frecuencia identificada con el pensamiento científico de Baranda, describe a los habitantes con términos fisiológicos:

La mesa remedaba un museo antropológico; había cráneos de todas hechuras: chatos, puntiagudos, lisos y protuberantes: caras anémicas y huesudas y falsamente sanguíneas y carnosas; cuellos espirales de flamenco y rechonchos de rana. Las fisonomías respiraban fatiga fisiológica de libertinos, modorra intelectual de alcohólicos y estupidez de caimanes dormidos. Lo que no impedía que cada cual aspirase, más o menos en secreto, a la Presidencia de la república (22).

En especial, en el momento de describir el físico de los políticos caribeños, el narrador alude a científicos de autoridad reconocida en la época. Por ello, al hablar del presidente contra el que Baranda urdía una rebelión que fracasó porque, en vísperas de la revuelta, los conspiradores se emborracharon $\mathrm{y}$, muertos de la risa, fueron a contarle al dictador cuales eran sus planes, la voz narrativa nos dice que el presidente era un negro que concordaba, física y moralmente con el tipo del criminal congénito de Cesare Lombroso (15) ${ }^{6}$. Asimismo, las reflexiones de Baranda se sustentan en los tratados científicos

cuando, por la misma voz narrativa sabemos que "Alicia era una india, delgada, esbelta, de regular estatura, de ojos de culebra, pequeños, maliciosos y vivos" (13). Todo ello hace totalmente discutible la teoría de Rosa sobre el propósito de Bobadilla de evidenciar el ascenso del mestizo en Cuba y, en particular, de la mujer mestiza.

6. Como es sabido, Cesare Lombroso (1835-1909) es considerado el padre de la antropología criminal. Sus teorías, derivadas de la frenología de Franz Gall, se apoyaban en estudios evolucionistas y 
que a fines del siglo XIX veían al hombre como un ser determinado por su especie:

No cabe duda - meditaba-. El hombre viene del mono e instintivamente miró a don Olimpio. No sólo tiene semejanza anatómica y fisiológica sino también psíquica. ¿Qué diferencia existe entre esa mona que da brincos y hace muecas y Petronio y Garibaldi? El orangután asiático y el gorila africano están más cerca de ellos, sin duda, que de los demás cinopitecos. La conclusión de Hartmann y Haeckel, de que entre los monos antropoideos y el hombre hay un parentesco íntimo, nunca le pareció tan evidente a Baranda como ahora $(48)^{7}$.

Pero donde la opinión ante la naturaleza humana de Baranda queda claramente expuesta es en la discusión que mantiene con Virgilio Zapote, médico de Ganga, con motivo de las condiciones en las que viven los reclusos. Basándose en la inexistencia del libre albedrío, Baranda cuestiona la responsabilidad que el criminal tiene sobre sus actos y critica el sistema penitenciario. Para Baranda, el encarcelamiento es una escuela de corrupción y el régimen celular un método de idiotización, y considera que deben buscarse las causas que llevan a un ser humano a realizar un acto delictivo. Cuando Zapote insiste en que los criminales son incorregibles y deben ser castigados, Baranda lo acusa de emitir sus juicios sin tener en cuenta al

genéticos y sostenían que ciertos criminales mostraban evidencia física de atavismo (características heredadas de antepasados lejanos) reminiscente de primitivos estadios de la evolución humana. Lombroso proponía el estudio de estas anomalías que consideraba reconocibles en las dimensiones de los cráneos, las mandíbulas y otras partes del cuerpo. Aunque sus teorías están totalmente desacreditadas en la actualidad, en su momento se consideraban indiscutibles y sus obras L'Uomo Delinquente (1876) y Le Crime, Causes et Remèdes (1899) eran pilares de la criminología moderna.

7. El narrador debe ref erirse a Eduard von Hartmann (1842-1906), autor de La filosofía del inconsciente (1884) y a Ernst Haeckel (1834-1919), científico evolucionista, que sostenían que todas las especies son entidades históricas (algo parecido a lo que cree el capitán del barcoque lleva a Baranda de Ganga a Guámbaro) y que el entorno actúa directamente en los organismos produciendo nuevas razas. Su afirmación de que la política es biología aplicada, fue utilizada, junto con sus justificaciones sobre el racismo, el nacionalismo y el darwinismo social, por el partido nazi. 
delincuente, sólo al delito, y el hacerlo de manera abstracta, sin considerar las teorías antropológicas expuestas por Lombroso sobre los rasgos físicos del delincuente, así como el determinismo de los factores sociales y físicos sobre el crimen. Es decir, con su postura ante el crimen, resulta evidente que Baranda piensa, como los escritores naturalistas, que el hombre no es un ser libre, ya que actúa impulsado por el peso de la herencia biológica y las circunstancias sociales.

En el mundo absurdo de Ganga o en el absurdo mundo al revés de Guámbaro, donde la población entera padece de la lepra, el bocio y la hidrocele ${ }^{8}$, los pocos personajes sensatos y cultos reflexionan de modo parecido a Baranda ${ }^{9}$. Así, Garibaldi Fernández, en un momento de lucidez, culpa al medio, concretamente al sol y al generalizado alcoholismo, de la de jadez general (51), al igual que Plutarco Álvarez, quien dice que en la capital hace frío y, por lo tanto, se puede estudiar, por lo que, a diferencia de la costa, hay allí personas cultas (69). Son. por lo tanto, el clima y el vicio los causantes de la desidia de las naciones tropicales. Con todo, el personaje que más analiza la situación es el capitán del barco que conduce al protagonista río arriba. Éste, ante todo, menciona lo impenetrable de la selva y el calor que hace imposible la explotación de las riquezas que atesora (la barbarie), pero, acto seguido, alude a la avaricia de los dirigentes, quienes piden empréstitos con la promesa de desarrollar el país y terminan embolsándose el dinero sin haber hecho nada por él. También critica la

8. La hidrocele es la hidropesía (acumulación anormal de humor seroso en las cavidades del cuerpo animal o su infiltración en el tejido celular) cuando se manifiesta en el testículo.

9. La descripción de Guámbaro recuerda el superlativismo grotesco de algunas novelas del boom: Baranda creyó morir de asco. ¡Todo un pueblo de leprosos paseándose en pleno día por las calles! Algunos padecían de hidrocele, pero tan hiperbólica, que hubiera creído que andaban en globo. Las mujeres del pueblo...ostentaban con orgullo el coto, repugnante bolsa gutural análoga a la del marabú de saco.

— ¡Ah, mira cómo tiene ese señor el cuello! — dijo un muchacho a su madre, señalando con el dedo al doctor.

- iAy, hijo, no le mires, no sea que Dios te castigue!

El coto, por lo visto, era en Guámbaro, no sólo natural, sino estético. Tener el cuello como le tiene la gente sana, se les antojaba ridículo (90). 
inconsistencia de los ideales políticos de los progresistas, siempre dispuestos a dejarse comprar a cambio de un puesto público que desempeñan sin estar capacitados para ello, y de los literatos esclavos de su ego y del gusto por la palabrería. El capitán, al igual que Baranda, tiene una formación cultural por encima de la de los demás, lo que le confiere autoridad en el momento de hablar, pero a diferencia del protagonista, él es un hombre valiente y enérgico, que ha luchado por su patria, la conoce y prefiere pasarse la vida capitaneando un miserable vapor fluvial que transigir con los causantes de la ruina del país. Es un claro representante del liberalismo progresista propio de algunas naciones hispanoamericanas, especialmente de aquéllas que consideraban el genocidio de los pueblos indígenas como un acto necesario para el establecimiento del orden nacional ${ }^{10}$. Así pues, en el momento de determinar el factor primordial que impide el progreso del país, el capitán señala al mulato y al negro, a quienes considera elementos raciales refractarios a toda disciplina, a todo orden y a toda moralidad, y termina con la siguiente diatriba:

en aquellos países donde el mulato y el indio no toman una parte tan activa en la vida social y política como entre nosotros, hay menos revueltas. Y se explica. Hay más unidad étnica. Me atrevería a afirmar que las luchas intestinas de un país responden en la mayoría de los casos a lo heterogéneo de su población... ¿Por qué Alemania e Inglaterra — para citar un ejemplo-

10. Un buen ejemplo de esta línea de pensamiento la encontramos en los discursos de un contemporáneo de Bobadilla, el mexicano Federico Gamboa (1864-1939), quien en un discurso dado ante la Escuela Nacional Preparatoria el 28 de septiembre de 1898, dijo: "Como excepciones que confirme la regla, veo de tiempo en tiempo colosales figuras de indios puros. Veo a Juárez, que me obliga a cerrar los ojos y a humillar la cerviz... Veo a Ignacio Altamirano, y elevan mi espíritu, les doy complacido mi admiración y aplauso, perofuera del tipo físico, no me resultan indios; si acaso ellos alardean de serlo, es por inocente coquetería de hombres superiores; son los primeros en comprender que su raza no produce individualidades de su talla... Su opaco color noes sino una equivocación de la naturaleza...el indio sin mezclas, el primitivo y legítimo, me apena; en ocasiones me avergüenza y hasta pienso que los Estados Unidos, la República Argentina y la República de Chile quizá han estado en lo exacto, cuando los han destruido o los han relegado a los desiertos, aunque con medida tal no se hayan acreditado de humanitarios". Federico Gamboa, Impresiones y recuerdos (México: Comel de la Puente Editor, 1922) 15. 
no dan casi nunca el espectáculo de los vergonzosos motines que se repiten en pueblos de abigarrada constitución mental? Le advierto, doctor, que yo no creo en las razas puras; yo creo en las razas históricas: las que, formándose por fusión de otras razas similares adquieren, al través de su historia, una fisonomía nacional... Para que vea usted que procuro no ser exclusivista, le concedo que los mulatos suelen ser músicos admirables, gente valerosa y lúbrica si la hubo (83-84).

Las palabras del capitán serían tan sólo el punto de vista de uno de los personajes si no fuera por la figura de Cándido Mestizo, un novelista mulato, que intenta objetar a las palabras del capitán y, al no poderlo hacer por reconocerse en lo que él dice, empieza a planear las intrigas mediante las cuales conseguirá que lo destituyan de su puesto, con lo que se confirma la opinión sustentada por el capitán.

Como he mencionado anteriormente, Baranda se diferencia del capitán en que no es un hombre de acción, sino un científico idealista o, como dice la voz narrativa, un soñador que cree que los pueblos cambian de hábitos mentales con una sangría colectiva (40). Al conocer a Alicia, advierte su temperamento nervioso, su carácter tenaz y autoritario, su cólera contenida, pero sólo piensa en poseerla y, cuando lo consigue, presiente algo funesto en esa relación, pero es el suyo un espíritu pusilánime que no sabe imponerse al medio ambiente y se deja arrollar por él. Cuando se casa con Alicia, no se preocupa en educarla y, cuando decrece la atracción física, se aleja de ella paulatinamente. Ella no se lo perdona, lo martiriza con sus escenas, sus gritos, sus escándalos, sus celos y sus pequeños robos, mezquindades de la vida doméstica contra las que el carácter abúlico y pasivo del médico no sabe, ni puede luchar. Como él mismo admite, el suyo no es un carácter ejecutivo y su afán por analizarlo todo paraliza su voluntad, ya que, al explicarse las causas del comportamiento de Alicia, lo disculpa mentalmente (122-123). Por supuesto, la explicación que Baranda se hace de la manera de ser de Alicia se acoge al 
determinismo causado por la herencia y el entorno. Según él, las causas de la histeria de la mujer son el haber crecido en un mosaico étnico en el que cada raza ha dejado su escoria (el indio su indolencia, el negro su lascivia y su inclinación por lo grosero, el conquistador su fanatismo religioso, el desorden administrativo y la falta de respeto por el ser humano), el ser hija de padres desconocidos que quizá fueron borrachos o histéricos, la influencia de un sol capaz de deshacer los sesos a cualquiera, y el establecerse sin ninguna preparación a la compleja y decadente civilización europea, de la que, con semejantes antecedentes, sólo puede asimilar lo nocivo (112-123). Lo cierto es que, con todo su poder de análisis, Baranda no tiene ningún interés en descubrir las verdaderas causas del comportamiento de Alicia. Por la voz narrativa conocemos que ya en Ganga, Alicia sólo era feliz cuando iba al campo y llevaba una vida de íntima comunidad con la naturaleza. Por ella misma sabemos de su extrañamiento en París, de la confusión en que la sumía el sentirse abandonada cuando el doctor salía de casa, dejándola sola en una ciudad en la que no sabía el idioma, ella, una mujer analfabeta en un país en el que no conocía a nadie. Así, aunque la voz de Baranda pretende afirmarse sobre todas las demás, el lector no puede dejar de comprender que la histeria de Alicia no tiene nada que ver con los genes, sino con el haber sido alejada del entorno que le es familiar y el haber sido lanzada a un mundo hostil para el que no ha recibido ninguna preparación. En Ganga, asediada por el grosero y lujurioso Olimpio, encontraba la paz en la naturaleza, pero la desquiciaba el verse perseguida noche y día por el hombre que le hacía de padre. Así pues, cansada de esta situación, decidió entregarse al refinado Baranda creyendo que éste le of recería una vida mejor y una posición social. Demasiado tarde advirtió que inclusive Baranda sólo estaba interesado en su físico. Mientras dura la pasión, Baranda no encuentra defectos en Alicia, a la que llama su salvajita, pero, cuando se cansa, vuelve con su amante de siempre y, ante las quejas de su esposa, le responde que con ella se aburre y termina echándole en cara su ignorancia. Alicia desarrolla entonces un odio total ante la maternidad, 
se provoca un aborto cuando queda embarazada y crea a su alrededor un ambiente hostil a su marido. Su comportamiento recuerda las selvas que Baranda ve en su viaje por el río, un entorno impenetrable, incapaz de dar fruto, cuyos únicos vestigios de civilización son las abandonadas locomotoras del fraude modernizador con el que se acercaron a ellas los que decían quererlas convertir en un ámbito cultivado y productivo.

La incapacidad de los efectos de la civilización europea sobre la barbarie se pone también de manifiesto en el destino de otros personajes que abandonan Ganga y se instalan en París. La segunda parte de la novela, además de relatarnos las desavenencias entre los Baranda, nos narra sarcásticamente la vida de los trasplantados:

¿Qué hacían... en París aquellos idiotas, groseros, chismosos y presumidos? Ir al Prentán o al Lubre, como ellos decían, pasearse en coche por el Bois, visitarse entre sí para comentar las noticias que recibían de sus respectivos países, siempre en guerra y tijeretearse los unos a los otros sin misericordia; hablar mal de los franceses, calificándolos de adúlteros falsos y frívolos, y alquilar, por último, durante el verano, villas y châlets en las playas más elegantes (112).

Todos ellos, salvo la ecuánime y sensata Nicasia, una viuda cubana que frecuenta a Alicia, odian al médico porque reconocen su superioridad. Al final, unos tienen que volver a Ganga porque se han arruinado, otros mueren debido a sus propios excesos y algunos ayudan a Alicia en su campaña contra el doctor.

En la segunda y tercera parte se insiste en las virtudes que hacen de Baranda un ser superior y es especialmente evidente la contraposición civilización / barbarie. Sin embargo, es también en estos capítulos donde es más difícil tener la seguridad sobre el punto de vista del autor implícito. Por un lado, Baranda nos es mostrado como un ser superior, víctima de la ruindad de Alicia y sus compatriotas pero, por otro, 
resulta incuestionable su falta de respeto hacia Alicia. Así, si se hace hincapié en la tortura psicológica a la que ésta somete al médico, queda también claro el egocentrismo de Baranda. Es éste un hombre que, aunque mucho más culto, adolece del mismo vicio de gustar oírse que tienen los poetastros de Ganga, se siente el centro del universo y, a su muerte, Alicia descubre desengañada que incluso su primer amor, que él contaba como una relación romántica y pura, no dejó de ser una simple relación carnal idealizada por la muerte de la novia ${ }^{11}$. Por último, su concepción de la vida sigue al pie de la letra los dictámenes de la ciencia pero, como les sucedía a los naturalistas, al querer ver en todo comportamiento un caso clínico, no tiene en cuenta la complejidad humana y, amparado por su objetividad de científico, hace el mal sin tener conciencia de ello ${ }^{12}$.

En conclusión, teniendo en cuenta la multiplicidad de voces de la novela, es posible afirmar que, para Bobadilla, la dicotomía civilización y barbarie se acerca más a la sustentada por los escritores modernistas y naturalistas hispanoamericanos y no a la anteriormente mencionada opinión de Martí. Es cierto que el texto denuncia la falsa

11. Resulta interesante este aspecto del relato. Baranda, como tantos enamorados de novelas modernistas, ha idealizado a su novia muerta, a la que recuerda como una virgen pura, pero a diferencia de los protagonistas de Sangre patricia y De sobremesa, Baranda tuvo relaciones sexuales con ella y ha inventado esa novela sentimental para satisfacer su propio ego. Cuando Alicia, quien admiraba a esa mujer que solamente con su pureza había sido capaz de inspirar tal amor en su marido, descubre que tras la sublimación sólo hay una sórdida historia de amor, se siente doblemente engañada por Baranda, ya que comprende el cúmulo de falsedades con las que su marido disf razaba en todo momento su profundo egocentrismo.

12. En dos ocasiones, Baranda da largas explicaciones culturales a sus amigos. Éstas nada tienen que ver con el argumento, pero develan un aspecto significativo sobre la personalidad del médico. La primera tiene lugar cuando Plutarco, al ver una multitud que aclama al Sha de Irán, le pregunta a Baranda si sabe algo de ese país, éste le contesta con varias páginas de historia antigua y cuando Plutarco le dice que quiere saber algo de la Persia moderna, su amigo le habla del fausto de los palacios, pero no of rece la más mínima inf ormación sobre la realidad social del país. La segunda charla cultural la encontramos en la tercera parte del libro, cuando la amante de Baranda menciona que todo en la naturaleza le parece inmóvil salvo el mar y él inicia entonces una conferencia sobre los cuerpos celestes. Ninguna de las dos explicaciones responde a la curiosidad de los que lo escuchan, pues en la primera Plutarco se queda sin saber como es la vida en Irán y, en la segunda, la amante del médico poco entiende de lo que él le dice y prefiere creer que una fuerza invisible mueve el universo. Ahora bien, ambas explicaciones muestran el ensimismamiento cultural de Baranda y su poca capacidad para entender la vida si no es a través de las páginas de los libros (11). 
modernización de Hispanoamérica al hablar de los trenes que pierden los vagones sin darse cuenta y, mientras la locomotora llega a su destino, el convoy vuelve, por su propia inercia, al punto de origen, $o$ al hablar de El buen gusto, el absurdo libro de buenos modales escrito por el desastrado Garibaldi, en el que se enseña a ceder el asiento a las señoras en el ómnibus cuando en Ganga no hay ningún tipo de servicio de transporte público. Pero la novela no habla de falsa erudición sino de una falsa voluntad civilizadora y de una barbarie sin esperanza, determinada por el entorno geográfico y por la herencia. Baranda encarna esta falsa voluntad civilizadora, acogiéndose a la personalidad de pensador naturalista, al que se le añade la misma falta de vigor del héroe decadentista hispanoamericano, egoísta y abúlico. Por otro lado, Alicia encarna la naturaleza determinada por la herencia, pero, asimismo, las malogradas posibilidades que, explícita o implícitamente, se advierten en esa naturaleza americana, a las que la civilización les ha negado toda posibilidad de desarrollo, deconstruyen las teorías deterministas de los intelectuales del periodo. Con lo que es posible afirmar que $A$ fuego lento rechaza por igual los esquemas simplificadores y las recetas científicas, mostrándonos que, como señala la cita de Flaubert con que se inicia el relato, el mensaje no se encuentra precisamente en aquello que se sostiene abiertamente sino en lo que el lector debe deducir a partir de lo contradictorio o injusto de lo que se niega o afirma. 